Revista de

Contabilidade e

Organizações
DOI: http://dx.doi.org/10.11606/rco.v8i21.55456
Journal of

Accounting and

Organizations

www.rco.usp.br

\title{
Aderência ao disclosure Relativo à ajuste a valor presente nas empresas listadas na Bm\&Fbovespa
}

Falber Cristiano Oliveira de Sousa ${ }^{\mathrm{a}}$, Patrícia Vasconcelos Rocha Mapurunga ${ }^{\mathrm{b}}$, Vera Maria Rodrigues Pontec;

"Universidade Federal do Ceará, Faculdade de Economia Adm., Atuária, Contab. e Secretariado e Executivo

${ }^{b}$ Tribunal de Contas do Estado do Ceara

- Universidade Federal do Ceará, Faculdade de Economia Adm., Atuária, Contab. e Secretariado e Executivo

\section{Informações do Artigo}

Histórico do Artigo

Recebido: 02 Maio 2013

Aceito: 04 Outubro 2014

Palavras chave

Disclosure.

Ajuste a Valor Presente.

Fatores Explicativos.

\begin{abstract}
Resumo
A presente pesquisa teve dois objetivos principais: levantar os graus de cumprimento às orientações de divulgação definidas no CPC 12 pelas companhias listadas na Bolsa de Valores, Mercadorias e Futuros (BM\&FBovespa); e identificar os incentivos capazes de explicar a aderência das firmas ao disclosure além da exigência normativa. Para tanto, a partir do normativo, construiu-se métrica de pesquisa contendo 17 itens passíveis de divulgação pelas firmas, e, em seguida, verificou-se a sua aderência por 315 companhias listadas na BM\&FBovespa. Constatou-se que as empresas apresentaram baixo grau de cumprimento às orientações de divulgação. A partir de testes de diferenças entre médias, verificou-se que as variáveis Setor Construção, Internacionalização, Firma de Auditoria e Governança Corporativa estão associadas às empresas de maiores níveis de disclosure. Além disso, com base na Análise de Regressão, não se pode rejeitar a hipótese de que o disclosure relativo ao Ajuste a Valor Presente pode ser explicado por fatores econômicos, patrimoniais e institucionais das firmas.
\end{abstract}

Copyright $(0) 2014$ FEA-RP/USP. Todos os direitos reservados

\section{INTRODUÇÃO}

A evidenciação, ou disclosure, de informações pelas firmas "envolve a ação de demonstrar para os usuários externos à organização o processo de reconhecimento e mensuração realizado" (LOPES; MARTINS, 2005, p. 51), auxiliando-os no processo decisório.

Dada a sua importância, o disclosure pode resultar tanto da decisão de prover maior número de informações aos usuários, quanto de obrigatoriedade normativa. Ou seja, as empresas podem prover o disclosure de forma voluntária ou por meio dos relatórios financeiros obrigatórios (HEALY; PALEPU, 2001).

Um exemplo da exigência de divulgação de informações são as normas internacionais de contabilidade, que preveem um conjunto de informações a serem obrigatoriamente divulgadas pelas empresas,

Corresponding author: Tel + 5585 3366-7827

E-mail : falbercristiano1@gmail.com (F. C. O. de Sousa), pattivasconcelos@hotmail.com (P. V. R. Mapurunga), vponte@fortalnet.com.br (V. M. R. Ponte)

Universidade Federal do Ceará, Faculdade de Economia Adm., Atuária, Contab. e Secretariado e Executivo - Av. da Universidade 2431 - Benfica 60020-180 - Fortaleza, CE - Brasil objetivando garantir mais qualidade informacional aos usuários.

No Brasil, essas normas são traduzidas e adaptadas pelo Comitê de Pronunciamentos Contábeis (CPC), cujos normativos, após referendados pelos respectivos órgãos reguladores, como a Comissão de Valores Mobiliários $(\mathrm{CVM})$, tornam-se obrigatórios às empresas (FIPECAFI, 2011).

Dentre esses normativos, destaca-se o pronunciamento técnico CPC 12 que discorre acerca do Ajuste a Valor Presente (AVP). Na opinião de Ponte, Oliveira e Cavalcante (2010, p. 5), “o AVP constitui um marco importante para os critérios de mensuração dos elementos patrimoniais na contabilidade brasileira", deslocando-a de uma posição puramente objetiva para uma posição de valor econômico, promovendo a divulgação de informações mais próximas da realidade econômica.

Nessa perspectiva, o CPC 12 define um conjunto de itens que devem ser observados quando da elaboração e publicação das demonstrações contábeis.

Ocorre que, a despeito da obrigatoriedade, estudo realizado por Ponte, Oliveira e Cavalcante (2010) indica um baixo grau de cumprimento dessa exigência pelas empresas listadas na BM\&FBovespa, no início da vigência das leis $\mathrm{n}^{\circ} 11.638 / 2007$ e $\mathrm{n}^{\circ} 11.941 / 2009$. 
Estudos de autores nacionais e estrangeiros constataram diferentes graus de cumprimento das normas internacionais, concluindo que, apesar de normativamente obrigatória, a divulgação das informações requeridas depende de incentivos específicos (FEKETE; MATIS; LUKÁCS, 2008; BOVA; PEREIRA, 2010; LIMA et al, 2010; MOURA et al, 2011; MAPURUNGA et al, 2011; MENESES; PONTE; MAPURUNGA, 2011).

Isso ocorreria quando o ambiente no qual as normas estão inseridas se caracterizava pelo baixo enforcement, caso em que as empresas poderiam decidir acerca da divulgação de informações na razão dos incentivos patrimoniais, econômicos etc., ainda que obrigatória.

Assim, considera-se na presente pesquisa que, apesar de os estudos classificados na categoria discretionarybased disclosure verificarem os incentivos para a divulgação voluntária (VERRECCHIA, 2001), seus pressupostos podem explicar a divulgação obrigatória quando, devido ao baixo enforcement, as empresas se arvoram no direito de selecionar as informações segundo suas conveniências.

Assumindo-se como premissa que as próprias empresas é que decidem quanto à divulgação das informações requeridas, e utilizando-se os pressupostos defendidos na categoria discretionary-based disclosure, formularam-se duas questões orientadoras do presente estudo: Qual o grau de cumprimento do disclosure requerido no CPC 12 - Ajuste a Valor Presente? Quais fatores explicam a observância das orientações de divulgação do CPC 12 ?

A partir da literatura disponível, bem como de resultados de pesquisas anteriores, elegeu-se como hipótese de pesquisa que nem todas as companhias observaram as orientações de divulgação do CPC 12, sendo o disclosure relativo ao AVP explicado por fatores econômicos, patrimoniais e institucionais.

Visando responder às questões formuladas, o presente estudo tem os seguintes principais objetivos: levantar, junto às companhias listadas na Bolsa de Valores, Mercadorias e Futuros (BM\&FBovespa), os respectivos graus de cumprimento às orientações de divulgação definidas no CPC 12; e investigar os incentivos capazes de explicar a aderência das firmas ao disclosure além da exigência normativa.

$\mathrm{Na}$ metodologia aplicada, realizou-se pesquisa bibliográfica e documental, procedendo-se à análise do conteúdo das notas explicativas às Demonstrações Financeiras Padronizadas (DFPs) das empresas não financeiras listadas na BM\&FBovespa. A amostra da pesquisa reuniu 315 companhias, 138 das quais admitiram expressamente haver aplicado o AVP no exercício de 2010.

Para a coleta dos dados, foi elaborada uma métrica contemplando os itens cuja divulgação é exigida pelo CPC 12 e verificou-se sua adesão pelas empresas. Após a catalogação dos dados, elaborou-se um Índice de Disclosure de AVP, seguindo-se a análise descritiva, bem como os testes de diferenças entre médias e a Análise de Regressão.
O presente artigo foi estruturado em cinco tópicos, incluindo esta introdução. O segundo apresenta o referencial teórico. $\mathrm{O}$ terceiro aborda os aspectos metodológicos da pesquisa. O quarto tópico traz os resultados da pesquisa e a sua análise. O estudo se encerra com a apresentação das conclusões.

\section{REFERENCIAL TEÓRICO}

\subsection{Disclosure de Informações Contábeis}

O disclosure constitui um importante instrumento de comunicação entre a empresa e seus grupos de interesse (BACKES, 2005), podendo ser entendido como sinônimo de divulgação ou evidenciação de informações (CRUZ; LIMA, 2010).

Backes (2005) afirma que o disclosure tem relação com os objetivos da contabilidade, cuja função, segundo a CVM (2008), consiste em fornecer informações úteis para subsidiar decisões e avaliações por parte dos usuários em geral.

No âmbito do mercado de capitais, o disclosure influencia o comportamento dos usuários e fornecedores das informações, já que afeta a percepção dos agentes econômicos quanto ao risco que a companhia oferece como também influencia decisões relacionadas ao grau de evidenciação, por sua vez condicionadas ao custo de sua implementação (CRUZ; LIMA, 2010). Segundo Cunha e Ribeiro (2008), a informação contábil desempenha papel fundamental na administração de conflitos de interesses, já que reduz a assimetria informacional entre gestores e investidores.

A assimetria informacional ocorre quando os investidores não recebem informações completas sobre a realidade econômica e financeira da empresa, ao passo que os gestores dispõem de vasto conteúdo informativo (SILVA, 2009). Diante disso, ao se disponibilizar informações para os usuários, diminui-se a assimetria informacional e, em consequência, os conflitos de interesse entre gestores $\mathrm{e}$ investidores, tal como propugnado pela Teoria da Agência (CARNEIRO, 2008).

Assim, vista a relevância do disclosure, conclui-se que sua eficácia depende da divulgação de informações que possibilitem aos usuários a compreensão das atividades desenvolvidas e dos riscos envolvidos, atentando-se para aspectos como tempestividade, detalhamento e relevância. Nesse sentido, Dantas et al (2005) afirmam que evidenciar não significa apenas divulgar, mas divulgar com qualidade, oportunidade e clareza.

Para atender às necessidades dos usuários, as empresas podem adotar diferentes métodos de evidenciação de informações qualitativas e quantitativas (AQUINO; FERREIRA, 2007). Iudícibus (1997) cita, dentre esses métodos, as notas explicativas, que, conforme, esclarece o CPC (2011), contêm informações adicionais em relação àquelas apresentadas nas demonstrações contábeis, descrevendo ou segregando itens ali contidos e informando sobre itens não enquadrados nos critérios de reconhecimento.

Lima, Fonseca e Brito (2009) ressaltam que o disclosure total de uma empresa não deve se restringir às informações exigidas por lei, devendo adicionar outras que possam vir a embasar decisões dos usuários. Nesse sentido, o disclosure pode ser compulsório, quando se 
refere a informações exigidas legalmente; ou voluntário, quando diz respeito a informações não obrigatórias, mas que trazem maior transparência ao âmbito corporativo.

A despeito da importância da divulgação de informações, um estudo investigativo quanto às informações de natureza avançada e não obrigatória evidenciadas pelas empresas brasileiras no exercício de 2006 (MELO; PONTE; OLIVEIRA, 2007) constatou que a evidenciação ainda apresentava índice abaixo do almejado pela sociedade.

Assim, a decisão pela divulgação voluntária de uma informação envolve várias questões. Teixeira (2010), por exemplo, enfatiza que as empresas têm divulgado informações voluntariamente como forma de se diferenciar no mercado de capitais. Yamamoto e Salotti (2006), por sua vez, entendem que devido aos elevados custos, a divulgação voluntária nem sempre é vantajosa, razão pela qual se dá a partir da ponderação entre custos e benefícios.

Segundo estudo de Verrecchia (2001) acerca da literatura sobre divulgação, as pesquisas sobre o tema podem ser agrupadas em três grandes categorias, a saber: Association-based disclosure, que investiga a relação entre a divulgação de determinada informação e o comportamento dos investidores; Discretionarybased disclosure, que procura identificar os motivos que levam a empresa a divulgar determinadas informações; e Efficiency-based disclosure, que estuda os tipos de divulgação preferida ou mais eficiente para subsidiar decisões dos stakeholders.

Nos estudos classificados na categoria Discretionarybased disclosure, o disclosure é tratado como uma decisão decorrente de um processo endógeno, em que os gestores e as organizações receberiam certos incentivos econômico-institucionais para divulgar informações de maneira voluntária (VERRECCHIA, 2001).

Ocorre que, quando é baixa a pressão dos órgãos normatizadores (MURCIA, 2009), ou mesmo quando as sanções pelo descumprimento da norma são demasiadamente leves ou inexistentes (BALL; KOTHARI; ROBIN, 2000), havendo, portanto, baixo enforcement, essa situação dá margem para que as próprias empresas decidam acerca da divulgação de informações obrigatórias, de acordo com suas conveniências.

Assim, pesquisas anteriores já utilizaram os pressupostos defendidos na categoria Discretionarybased disclosure e investigaram a relação entre o disclosure e algumas variáveis representativas dos incentivos para a divulgação de informações voluntárias e/ou obrigatórias.

\subsubsection{Estudos Empíricos Anteriores}

Cunha e Ribeiro (2008) investigaram as companhias com ações negociadas no mercado de capitais brasileiro, no que tange aos incentivos para divulgação voluntária de informações sociais, e constataram que a divulgação voluntária tem associação positiva com variáveis como nível de governança corporativa, desempenho, tamanho e divulgação em período anterior.

Alencar (2007) investigou a relação entre disclosure e custo de capital próprio no Brasil, encontrando uma relação negativa e estatisticamente significante entre essas variáveis. Já Lima (2007), considerando a relação entre o nível de disclosure voluntário e o custo de capital de terceiros, constatou que o custo de capital de terceiros é inversamente proporcional ao nível de disclosure voluntário.

Costa, Goldner e Galdi (2007) investigaram os maiores bancos brasileiros e identificaram que os fatores que mais influenciam o disclosure voluntário são: independência do Conselho de Administração, tamanho da empresa, listagem de suas ações no mercado de capitais, emissão de American Depositary Receipts (ADRs) na Bolsa de Nova Iorque e nível diferenciado de governança corporativa da BM\&FBovespa.

Estudo realizado por Pereira et al (2008) concluiu que há uma relação positiva entre o grau de disclosure e o lucro contábil. Além disso, foi confirmada a hipótese de que o tamanho da empresa, a adesão a um dos níveis de governança corporativa e a participação de acionistas controladores estrangeiros também contribuiriam para elevar o nível de evidenciação.

Murcia (2009) procurou identificar os fatores que explicam o nível de disclosure voluntário das empresas abertas brasileiras e, a partir de uma métrica, contemplando grupos de disclosure: econômico, social e ambiental, concluiu que as variáveis setor e origem do controle eram significativas para os três grupos de disclosure; que as variáveis endividamento, auditoria e rentabilidade eram significativas apenas no grupo econômico; e que as variáveis tamanho, governança e emissão de ações não eram significativas em nenhum dos três grupos.

Mais recentemente, Mapurunga et al (2011) pesquisaram sobre a associação entre disclosure de instrumentos financeiros derivativos - CPC 14 - e características econômicas de empresas de capital aberto, concluindo que os atributos tamanho e lucro estão positivamente associados ao disclosure.

Meneses, Ponte e Mapurunga (2011) estudaram a associação entre a divulgação de informações acerca dos ativos intangíveis requeridas pelo CPC 04 e as características econômicas das companhias listadas na BM\&FBovespa e constataram que havia indicativo de associação positiva entre o lucro e o disclosure de ativos intangíveis, embora o estudo não tenha sido conclusivo.

Abordando a divulgação de informações referentes ao AVP, Ponte, Oliveira e Cavalcante (2010) concluíram que a transparência foi negligenciada nas demonstrações, bem como não observam um maior atendimento às orientações de divulgação por parte empresas listadas nos níveis diferenciados da BM\&FBovespa.

\subsection{Ajuste a Valor Presente (AVP)}

O AVP é "a estimativa do valor corrente de um fluxo de caixa futuro, no curso normal das operações da entidade" (CPC, 2008, p.12) e tem por finalidade apresentar o Ativo ou o Passivo em valores condizentes com a data da publicação do Balanço Patrimonial ou a data de encerramento do exercício (QUEIROZ et al, 2010).

Segundo a Fipecafi (2010, p. 105), “a técnica de redução a valor presente de contas a receber e a pagar não é nova. A sua mensuração decorre dos conceitos de 
avaliação de ativos e passivos a valores de saída".

No Brasil, o AVP foi expressamente inserido na Lei das Sociedades por Ações com o advento da lei $\mathrm{n}^{\circ}$ $11.638 / 2007$, que acrescentou a obrigatoriedade de se proceder ao AVP nos elementos provenientes de operações de longo prazo classificados no Ativo, nas obrigações, nos encargos e riscos de longo prazo classificados no Passivo, assim como em outros elementos do Ativo e do Passivo de curto prazo, quando existir efeito relevante (BRASIL, 2007).

Essa mudança "tem o objetivo de determinar as parcelas de ativo e passivo que não correspondem a preço efetivo da transação, mas sim a ajuste por conta do valor do dinheiro no tempo" (FIPECAFI, 2010, p. 106). No mesmo sentido, Moribe, Panosso e Marroni (2007, p. 23) observam que "para aplicação do ajuste a valor presente necessita-se reconhecer o valor do dinheiro no tempo. Sendo assim, valor presente é o valor atual de um montante futuro".

Ressalta-se que, apesar da inovação introduzida pela lei ${ }^{\circ} 11.638 / 2007$, o AVP não é assunto totalmente novo no Brasil, já que em 1992 a CVM publicou a Instrução Normativa $n^{\circ} 192$, que já abordava o AVP (QUEIROZ et al, 2010).

Já em 2008, no contexto da convergência para as normas internacionais de contabilidade, foi emitido o CPC 12, aprovado pela Deliberação CVM nº 564/2008. O CPC 12 estabeleceu os requisitos a serem observados quando se apura o AVP de elementos do Ativo e do Passivo na data da elaboração das demonstrações contábeis, bem como esclareceu os pontos controversos decorrentes de tal procedimento (CPC, 2008).

De acordo com Ernst \& Young Terco (2011), o CPC 12 foi emitido tendo em vista o dia a dia corporativo do Brasil, já que as taxas de juros no país tendem a ser maiores do que aquelas praticadas nos Estados Unidos e em outros países desenvolvidos, o que ocasiona um ajuste expressivo do valor presente de um ativo. Moribe, Panosso e Marroni (2007, p. 22) assim se expressam sobre a questão:

Considerando o impacto que os juros prefixados provocam nas transações, as demonstrações contábeis, ao serem elaboradas em dado período, não refletem a realidade daquele momento. Desse modo, torna-se importante que tais transações geradoras de Direitos e Obrigações futuras em montantes prefixados sejam traduzidas a valor presente nos respectivos registros contábeis, fazendo o expurgo dos juros embutidos, tornando os valores compatíveis à época da transação.

De acordo com a Fipecafi (2010, p. 106), o AVP "contribui para a elaboração de demonstrações contábeis com maior valor preditivo e, se tais informações são registradas de modo oportuno, também contribuirão para o aumento do grau de relevância das demonstrações contábeis". CPC (2008, p. 2) acrescenta que o AVP "permite a correção de julgamentos acerca de eventos passados já registrados; e traz melhoria na forma pela qual eventos presentes são reconhecidos".

Ressalta-se que o CPC 12 trata especificamente de questões relativas à mensuração do AVP, não abordando detalhes referentes a reconhecimento. No tocante à evidenciação, afirma que a entidade deve disponibilizar informações mínimas que facilitem o entendimento inequívoco da forma como os ativos e passivos tenham sido mensurados a valor presente (CPC, 2008).
Assim, o CPC (2008, p. 10) orienta que "devem ser prestadas informações mínimas que permitam que os usuários das demonstrações contábeis obtenham entendimento inequívoco das mensurações a valor presente levadas a efeito para ativos e passivos", descrevendo, no item 33 do CPC 12, um conjunto mínimo de informações que devem ser divulgadas para atender a esses requisitos.

Dessa forma, é evidente a preocupação do normativo com a divulgação de informações acerca dos AVPs realizados, já que essas informações possibilitarão a melhor análise e, consequentemente, as melhores decisões por parte dos agentes econômicos.

\section{METODOLOGIA}

\subsection{Desenho da Pesquisa}

Quanto aos objetivos, a pesquisa pode ser classificada como exploratória e descritiva. Quanto à natureza, a pesquisa se caracteriza como de abordagem quantitativa, já que empregou métodos estatísticos, com utilização de procedimentos bibliográficos e documentais, sendo a coleta de dados realizada por meio da Análise de Conteúdo.

A população da pesquisa reuniu as 445 empresas listadas na BM\&FBovespa no exercício de 2010, das quais foram excluídas, para compor a amostra, 51 empresas que divulgaram, nas notas explicativas às demonstrações financeiras, informações que levaram a inferir que o normativo não lhes era aplicável, bem como as demais empresas consignadas na Tabela 1.

Tabela 1. Formação da amostra da pesquisa

\begin{tabular}{c|c}
\hline População & $\mathbf{4 4 5}$ \\
\hline Empresas do setor finanças e seguros & $(66)$ \\
\hline $\begin{array}{c}\text { Empresa cujas DFPs não foram disponibilizadas no } \\
\text { portal eletrônico da BM\&FBovespa }\end{array}$ & $(13)$ \\
\hline $\begin{array}{c}\text { Empresas que divulgaram, nas notas explicativas às } \\
\text { demonstrações financeiras, informações que levaram a } \\
\text { inferir que o normativo não lhes era aplicável }\end{array}$ & $(51)$ \\
\hline AMOSTRA & 315 \\
\hline
\end{tabular}

Fonte: Dados da pesquisa.

Definida a amostra do estudo, examinaram-se as notas explicativas das respectivas DFPs. Primeiramente, realizou-se levantamento para identificação das empresas que mencionavam o AVP no exercício de 2010, ou seja, aquelas que evidenciavam expressamente acerca da aplicabilidade do CPC 12.

Verificou-se, então, que, das 315 empresas da amostra, 177 nada informaram acerca da realização de AVP no período, ao passo que 138 empresas informaram haver aplicado o AVP e registrado os impactos dessa aplicação nas demonstrações contábeis. Para essas companhias, foram levantadas as práticas de divulgação acerca da aplicação do AVP. 
Para tanto, desenvolveu-se uma métrica contemplando as exigências de divulgação presentes no referido normativo, e em seguida verificou-se a adesão das empresas, empregando-se a Análise de Conteúdo, proposta por Bardin (2011). Assim, as informações requeridas pelo CPC 12 foram desmembradas ao máximo para que não houvesse margem para atendimento parcial, ficando a métrica composta por 17 itens de evidenciação.

Após classificadas de acordo com a métrica, cada informação foi valorada conforme sua condição, tal como preconizado por Bardin (2011), atribuindo-se "um" quando a informação requerida estava presente, e "zero" no caso contrário.

Além disso, verificou-se ainda se o item passível de divulgação era aplicável à empresa, de modo a evitar penalização indevida ao se atribuir "zero" nos casos de falta de divulgação de informações que não fossem aplicáveis, como defendido por Owusu-ansah (1998).

Ou seja, nos casos em que as empresas evidenciaram expressamente que o evento não ocorreu, as respectivas informações decorrentes do evento foram consideradas não aplicáveis às respectivas empresas, de maneira que os respectivos itens não fossem considerados na formação do denominador do Índice de Disclosure.

Assim, cada empresa possuía um número de informações aplicáveis, de modo que, ao final, o Índice de Disclosure do AVP de cada empresa resultou da relação entre o número de informações divulgadas e o número de informações que lhe eram aplicáveis, cabendo a cada companhia um valor compreendido entre $0 \%$ (caso das empresas que não evidenciaram nenhum dos itens requeridos pelo CPC 12 a elas aplicáveis) e 100\% (caso daquelas que divulgaram todos os itens a elas aplicáveis).

\subsection{Variáveis, Modelo e Processamento}

De posse do Índice de Disclosure do AVP, foram utilizadas técnicas estatísticas descritivas, de maneira a viabilizar a realização de uma análise sobre a divulgação das informações pelas firmas, além de uma análise geral das variáveis utilizadas na pesquisa. Além disso, realizaram-se testes de diferenças de médias não paramétricos, de modo a se comparar possíveis diferenças entre os grupos das variáveis de natureza qualitativa (Setor, Internacionalização, Auditoria e Governança Corporativa).

Na sequência, e para atender ao objetivo da pesquisa, utilizou-se a Análise de Regressão. Para compor o modelo de Análise de Regressão, foram selecionados fatores econômicos, patrimoniais e institucionais das firmas a partir de evidências empíricas e bibliográficas que permitiram considerar que esses são capazes de explicar a aderência das firmas brasileiras ao CPC 12 .

Desse modo, foram selecionadas as variáveis quantitativas (i) Tamanho, (ii) Rentabilidade, (iii) Endividamento - medidas a partir das proxies mostradas na Tabela 2; e as variáveis qualitativas (iv) Internacionalização, (v) Firma de Auditoria, (vi) Governança Corporativa e (vii) Setor - quantificadas atribuindo-se o valor " 1 " na presença do atributo constante do Quadro 1, e o valor " 0 " no caso contrário.

\begin{tabular}{|c|c|}
\hline VARIÁVEL & PROXY/ATRIBUTO \\
\hline Tamanho & $=$ Ativo Total \\
\hline Rentabilidade & $\begin{array}{c}\text { = Lucro Líquido / Patrimônio Líquido } \\
\text { (ROE) }\end{array}$ \\
\hline Endividamento & $=$ Passivo Oneroso $/$ Ativo Total \\
\hline Internacionalização & $\begin{array}{c}=\text { Empresas nacionais com ações negociadas } \\
\text { em bolsas estrangeiras }\end{array}$ \\
\hline Firma de Auditoria & $\begin{array}{c}=\text { Empresas auditadas por "big four" (Ernst } \\
\text { \& Young, Deloitte, PWC e KPMG) }\end{array}$ \\
\hline \multirow{2}{*}{$\begin{array}{l}\text { Governança } \\
\text { Corporativa }\end{array}$} & $\begin{array}{c}\text { Empresas listadas nos níveis } \\
\text { diferenciados de governança corporativa da } \\
\text { BM\&FBovespa }\end{array}$ \\
\hline & $\begin{array}{c}=\text { Respectivos setores de atividade - } \\
\text { classificação Economática }\end{array}$ \\
\hline
\end{tabular}

Quadro 1. Variáveis representativas dos incentivos econômicos

Assim, o modelo de regressão ficou assim equacionado:

$D I S C=\beta_{0}+\beta_{1} T A M+\beta_{2} E N D+\beta_{3} I N T+\beta_{4} F A+\beta_{5} G O V+\beta_{6} S E T+\beta_{7}$ $+\varepsilon$

Em que:

DISC: Disclosure

$\beta$ : coeficientes do modelo

TAM: Tamanho

RENT: Rentabilidade

END: Endividamento

INT: Internacionalização

FA: Firma de Auditoria

GOV: Governança Corporativa

SET: Setor

$\varepsilon$ : é o erro do modelo.

Os dados para compor tais variáveis foram coletados junto à base de dados Economática ${ }^{\circledR}$ e nos websites da CVM e da BM\&FBovespa, em dezembro de 2011.

$\mathrm{Na}$ Análise de Regressão, verificaram-se os principais pressupostos nomeados por Cunha e Coelho (2011, p. 151), quais sejam: "normalidade dos resíduos, homocedascidade dos resíduos, linearidade dos coeficientes, ausência de autocorrelação serial nos resíduos e multicolinearidade entre as variáveis independentes".

\section{ANÁLISE DOS RESULTADOS}

Observou-se, inicialmente, a aplicabilidade do CPC 12 às empresas da amostra. Essa fase foi necessária para que os itens de divulgação ali exigidos pudessem ser computados para o cálculo do Índice de Disclosure do AVP das empresas para as quais eram aplicáveis, conforme destacado na metodologia do presente estudo.

A aplicabilidade foi verificada por meio do exame das notas explicativas às DFPs das empresas da amostra. 
Observou-se que algumas empresas deixaram de informar sobre a ocorrência do AVP, não sendo possível, nesses casos, concluir com total certeza sobre a aplicabilidade do CPC 12.

Verificou-se que, do total de 366 empresas pesquisadas, 189 mencionaram a prática do AVP, enquanto 177 não fizeram nenhum tipo de comentário relacionado a tal prática em suas notas explicativas, caso em que a aplicabilidade do CPC 12 não estava expressa. Nessa situação, não se pôde concluir com exatidão se a empresa deixou de divulgar a informação porque o normativo não lhe era aplicável ou porque, mesmo sendo-lhe aplicável, decidiu não divulgar.

Já por meio do exame das notas explicativas das 189 empresas que comentaram acerca do AVP, foi possível verificar que 138 delas realizaram o procedimento contábil e registraram seus impactos, deixando expressa a aplicabilidade do CPC 12; as demais (51) informaram não haver contabilizado os efeitos do AVP, devido a sua irrelevância, ou por não possuir ativos e passivos que necessitassem do AVP, casos em que o CPC 12 foi considerado não aplicável, conforme demonstrado na Tabela 2.

Tabela 2. Aplicabilidade do CPC 12

\begin{tabular}{l|c|c}
\hline \multicolumn{1}{c|}{ Situação } & $\begin{array}{c}\mathrm{N}^{\circ} \text { de } \\
\text { Empresas }\end{array}$ & $\begin{array}{c}\text { Proporção } \\
\text { (\%) }\end{array}$ \\
\hline Não fez referência ao AVP & 177 & 48,4 \\
\hline $\begin{array}{l}\text { Aplicabilidade estava } \\
\text { expressa }\end{array}$ & 138 & 37,7 \\
\hline $\begin{array}{l}\text { Não aplicabilidade estava } \\
\text { expressa }\end{array}$ & 51 & 13,9 \\
\hline Total & 366 & 100,0 \\
\hline
\end{tabular}

Fonte: Dados da pesquisa.

Dos dados consignados na Tabela 2, conclui-se que, levando-se em conta que a não-divulgação não necessariamente significa que o normativo não é aplicável à empresa, já que os próprios normativos chamam a atenção para a divulgação em caso de não aplicabilidade, as 177 empresas que nada divulgaram acerca do AVP não podem ser excluídas da amostra. Por esse motivo, essas empresas obtiveram um Índice de Disclosure de $0 \%$, sendo-lhes aplicáveis todos os 34 itens de evidenciação.

Além disso, 138 empresas realizaram o AVP e registraram os impactos em suas demonstrações contábeis, divulgando itens requeridos pelo CPC 12. Diante disso, apenas para fins de análise dos itens divulgados pelas empresas, considerar-se-ão apenas essas 138 empresas, tal como apresentado no item 4.1. Já para fins de realização de estatística descritiva e aplicação de testes de diferenças de médias e Análise de Regressão, serão consideradas todas as 315 empresas da amostra.

\subsection{Análise dos Itens Divulgados pelas Empresas}

No que tange aos itens divulgados pelas 138 empresas que evidenciaram os impactos do AVP, constatou-se que seis itens (cerca de $35 \%$ dos 17 ) não foram divulgados por nenhuma das empresas, bem como que cinco itens (cerca de 30\%) foram divulgados por menos de $10 \%$ delas, conforme explicitado na Tabela 3. Esses resultados retratam um baixo índice de aderência ao CPC 12 já que onze itens (aproximadamente 65\%) foram divulgados por poucas empresas ou não foram divulgados.
Dentre os itens mais divulgados, observa-se que nenhum deles chegou a ser evidenciado pela totalidade das empresas. Com efeito, a subcategoria "Divulga a descrição pormenorizada do item objeto da mensuração a valor presente?" foi divulgada por $95,65 \%$ das 138 empresas, seguido das subcategorias "Divulga as premissas utilizadas pela administração?", divulgado por $80,43 \%$, e "Divulga as taxas de juros utilizadas?", divulgado por $62,32 \%$. A Tabela 3 evidencia as quantidades e as proporções de divulgação dos itens do CPC 12.

Tabela 3. Distribuição quantitativa e proporcional das empresas segundo a divulgação dos 17 itens do CPC 12

\begin{tabular}{|c|c|c|}
\hline Subcategoria & 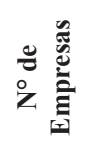 & 育 \\
\hline $\begin{array}{l}\text { Divulga a descrição pormenorizada } \\
\text { do item objeto da mensuração a valor } \\
\text { presente? }\end{array}$ & 132 & 95,7 \\
\hline $\begin{array}{l}\text { Divulga a natureza de seus fluxos de } \\
\text { caixa (contratuais ou não)? }\end{array}$ & 25 & 18,1 \\
\hline $\begin{array}{l}\text { Divulga, se aplicável, o valor de entrada } \\
\text { cotado a mercado? }\end{array}$ & 0 & 0,0 \\
\hline $\begin{array}{l}\text { Divulga as premissas utilizadas pela } \\
\text { administração? }\end{array}$ & 111 & 80,4 \\
\hline $\begin{array}{l}\text { Divulga as taxas de juros decompostas } \\
\text { por prêmios incorporados? }\end{array}$ & 0 & 0,0 \\
\hline $\begin{array}{l}\text { Divulga as taxas de juros decompostas } \\
\text { por fatores de risco (risk-free, risco de } \\
\text { crédito, etc.)? }\end{array}$ & 27 & 19,6 \\
\hline Divulga as taxas de juros utilizadas? & 86 & 62,3 \\
\hline $\begin{array}{l}\text { Divulga os montantes dos fluxos de } \\
\text { caixa estimados ou séries de montantes } \\
\text { dos fluxos de caixa estimados? }\end{array}$ & 2 & 1,4 \\
\hline $\begin{array}{l}\text { Divulga o horizonte temporal estimado } \\
\text { ou esperado? }\end{array}$ & 4 & 2,9 \\
\hline $\begin{array}{l}\text { Divulga expectativas em termos de } \\
\text { montante? }\end{array}$ & 10 & 7,2 \\
\hline $\begin{array}{l}\text { Divulga a temporalidade dos fluxos } \\
\text { (probabilidades associadas)? }\end{array}$ & 0 & 0,0 \\
\hline $\begin{array}{l}\text { Divulga os modelos utilizados para } \\
\text { cálculo de riscos? }\end{array}$ & 0 & 0,0 \\
\hline Divulga os inputs dos modelos? & 0 & 0,0 \\
\hline $\begin{array}{l}\text { Divulga breve descrição do método de } \\
\text { alocação dos descontos? }\end{array}$ & 32 & 23,2 \\
\hline $\begin{array}{l}\text { Divulga o procedimento adotado para } \\
\text { acomodar mudanças de premissas da } \\
\text { administração? }\end{array}$ & 1 & 0,7 \\
\hline $\begin{array}{l}\text { Divulga o propósito da mensuração a } \\
\text { valor presente? }\end{array}$ & 9 & 6,5 \\
\hline $\begin{array}{l}\text { Se o propósito for para nova medição, } \\
\text { em vez de reconhecimento inicial, } \\
\text { divulga a motivação da administração } \\
\text { para levar a efeito tal procedimento? }\end{array}$ & 0 & 0,0 \\
\hline
\end{tabular}

Fonte: Dados da pesquisa. 


\subsection{Estatística Descritiva e Testes de Diferenças de Médias}

A Tabela 4 evidencia algumas medidas estatísticas descritivas referentes ao Indice de Disclosure das 315 empresas em que o normativo foi considerado aplicável.

Tabela 4. Estatística descritiva - Índice de Disclosure das 315 empresas da amostra

\begin{tabular}{c|c|c|c|c|c}
\hline Média & $\begin{array}{c}\text { Desvio- } \\
\text { padrão }\end{array}$ & Moda & Med & Mín & Máx \\
\hline $8,5 \%$ & $11 \%$ & $0 \%$ & $0 \%$ & $0 \%$ & $50 \%$ \\
\hline
\end{tabular}

Fonte: Dados da pesquisa.

Em média, as 315 companhias analisadas obtiveram um Índice de Disclosure do AVP de 8,5\%, com um desvio-padrão de $11 \%$. A medida retromencionada revela que as empresas divulgaram, em média, 1,5 dos 17 itens requeridos pelo CPC 12.

O Índice de Disclosure mais frequente foi de $0 \%$, registrado pelas 177 empresas que não divulgaram nenhuma informação acerca do AVP. Pelo mesmo motivo, a mediana também foi de $0 \%$, demonstrando que pelo menos metade das empresas não divulgou nenhum item requerido pelo $\mathrm{CPC} 12$

Além disso, considerando-se, para fins de análise, apenas as 138 companhias que deixaram expressa a ocorrência do AVP, o Índice de Disclosure também foi baixo, já que, em média, essas 138 companhias resultados mostrados na Tabela 6 . obtiveram um Índice de Disclosure do AVP de 19,3\%, com desvio-padrão de 8,1\%, conforme Tabela 5. Ou seja, essas empresas divulgaram, em média, três dos 17 itens requeridos pelo CPC 12 .

Tabela 5. Estatística descritiva - Índice de Disclosure das 138 empresas que deixaram expressa a ocorrência de AVP

\begin{tabular}{c|c|c|c|c|c}
\hline Média & $\begin{array}{c}\text { Desvio- } \\
\text { padrão }\end{array}$ & Moda & Med & Mín & Máx \\
\hline $19,3 \%$ & $8,1 \%$ & $17,7 \%$ & $17,7 \%$ & $5,9 \%$ & $47,1 \%$ \\
\hline
\end{tabular}

Fonte: Dados da pesquisa.

Ocorre que, a despeito do baixo grau de atendimento às exigências de divulgação do CPC 12 no exercício de 2010, o Índice de Disclosure das empresas variou, ressaltando-se que duas empresas se destacaram por divulgar maior número de informações, apresentando índices de 47\% e 44\%. Nas demais empresas, esse índice variou de $0 \%$ a $40 \%$.

Assim, como as empresas apresentaram diferentes níveis de disclosure, é possível que outros fatores influenciem a decisão pela divulgação dessas informações, além da exigência normativa.

Nessa perspectiva, agrupando-se as empresas da amostra de acordo com as variáveis representativas dos incentivos econômicos (Setor, Internacionalização, Firma de Auditoria e Governança Corporativa), é possível verificar estatisticamente se as médias dos índices de disclosure dessas empresas são diferentes, conforme

Tabela 6. Resultados dos testes de diferenças de médias

\begin{tabular}{|c|c|c|c|c|c|c|}
\hline Variável & Grupo & Média (\%) & $\begin{array}{c}\text { Desvio-padrão } \\
(\%)\end{array}$ & Mínimo (\%) & Máximo (\%) & Teste $\mathbf{Z}$ \\
\hline \multirow{20}{*}{ Setor } & Agro e Pesca & 17,6 & & 17,6 & 17,6 & \multirow{19}{*}{$40,885^{*}$} \\
\hline & Alimentos e Bebidas & 8,6 & 10,0 & 0,0 & 23,5 & \\
\hline & Comércio & 10,9 & 9,2 & 0,0 & 23,5 & \\
\hline & Construção & 20,7 & 14,3 & 0,0 & 47,1 & \\
\hline & Eletroeletrônicos & 8,2 & 11,5 & 0,0 & 23,5 & \\
\hline & Energia Elétrica & 7,2 & 10,5 & 0,0 & 29,4 & \\
\hline & Máquinas Industriais & 8,8 & 11,3 & 0,0 & 23,5 & \\
\hline & Mineração & 5,9 & 11,3 & 0,0 & 29,4 & \\
\hline & Minerais não Metálicos & 5,9 & 6,8 & 0,0 & 11,8 & \\
\hline & Outros & 5,4 & 10,4 & 0,0 & 50,0 & \\
\hline & Papel e Celulose & 1,2 & 2,6 & 0,0 & 5,9 & \\
\hline & Petróleo e Gás & 1,5 & 2,7 & 0,0 & 5,9 & \\
\hline & Química & 8,0 & 8,8 & 0,0 & 23,5 & \\
\hline & Siderurgia e Metalurgia & 7,5 & 10,5 & 0,0 & 29,4 & \\
\hline & Software e Dados & 9,8 & 12,2 & 0,0 & 23,5 & \\
\hline & Telecomunicações & 11,3 & 9,4 & 0,0 & 23,5 & \\
\hline & Têxtil & 9,2 & 10,3 & 0,0 & 29,4 & \\
\hline & Transporte e Serviço & 11,8 & 9,8 & 0,0 & 29,4 & \\
\hline & Veículos e Peças & 7,1 & 11,6 & 0,0 & 29,4 & \\
\hline & Total & 8,5 & 11,0 & 0,0 & 50,0 & \\
\hline \multirow{3}{*}{ Internacionalização } & Não & 7,2 & 10,3 & 0,0 & 37,5 & \multirow{2}{*}{$-3,319 *$} \\
\hline & Sim & 12,1 & 12,4 & 0,0 & 50,0 & \\
\hline & Total & 8,5 & 11,0 & 0,0 & 50,0 & \\
\hline \multirow{3}{*}{ Firma de Auditoria } & Não & 4,3 & 7,8 & 0,0 & 31,3 & \multirow{2}{*}{$-4,426^{*}$} \\
\hline & Sim & 10,2 & 11,7 & 0,0 & 50,0 & \\
\hline & Total & 8,5 & 11,0 & 0,0 & 50,0 & \\
\hline \multirow{3}{*}{ Governança Corporativa } & Não & 5,8 & 9,0 & 0,0 & 29,4 & \multirow{2}{*}{$-5,004 *$} \\
\hline & Sim & 12,3 & 12,5 & 0,0 & 50,0 & \\
\hline & Total & 8,5 & 11,0 & 0,0 & 50,0 & \\
\hline
\end{tabular}

Para a variável Setor, foi utilizado o teste de diferenças de médias de Kruskal-Wallis; para as demais, foi utlizado o teste $U$ de Mann-Whitney. 
Pela análise da significância dos testes de diferenças de médias, pode-se perceber que todos os grupos de variáveis apresentam médias estatisticamente diferentes, ao nível de $1 \%$, bem como que as variáveis Setor Construção, Internacionalização, Firma de Auditoria e Governança Corporativa estão associadas às empresas com maiores níveis de disclosure.

Logo, há indício de que as empresas classificadas no Setor Construção apresentam maiores níveis de disclosure, bem como que as empresas com ações negociadas em bolsas estrangeiras, são auditadas por uma Big Four e participam dos níveis diferenciados da BM\&FBovespa também apresentam maiores níveis de disclosure.

\subsection{Análise de Regressão}

Na aplicação da Análise de Regressão, verificaram-se, inicialmente, as correlações entre as variáveis em estudo, no intuito de se identificar possíveis associações entre a variável dependente e as variáveis independentes, bem como indícios de multicolinearidade entre as variáveis independentes.

Dentre as possíveis correlações entre variável dependente e variáveis independentes, constatou-se uma associação entre o disclosure e as variáveis Tamanho, Endividamento, Internacionalização, Firma de Auditoria e Governança Corporativa, a um nível de significância de $1 \%$.

Quanto à existência de multicolinearidade, não se verificou alto coeficiente de correlação entre quaisquer variáveis independentes, não havendo, portanto, indício de multicolinearidade.

Com o objetivo de se garantir a homocedasticidade dos resíduos, utilizou-se a correção robusta de White, e, com base no Teorema do Limite Central, presumiu-se a normalidade dos resíduos, já que a amostra utilizada possui observações em quantidade compatível com tal pressuposto. Além disso, como não se utilizaram séries temporais, sendo os dados cross-section, não se faz necessário verificar o pressuposto de ausência de autocorrelação, sendo, portanto, atendidos todos os pressupostos da regressão.

Tabela 7. Modelo de regressão

\begin{tabular}{|c|c|c|c|c|}
\hline Variável & Expectativa & Coeficiente & t teste & P-valor \\
\hline Tamanho & + & 0,0154239 & 3,10 & $0,002 * * *$ \\
\hline Rentabilidade & + & 0,0061131 & 0,78 & 0,439 \\
\hline Enddividamento & + & 0,0613427 & 2,65 & $0,008 * * *$ \\
\hline Internacionalização & + & $-0,0015311$ & $-0,09$ & 0,929 \\
\hline Firma de auditoria & + & 0,0220425 & 1,62 & 0,106 \\
\hline Governança corporativa & + & 0,0367495 & 2,44 & $0,015^{* *}$ \\
\hline Setor agro e pesca & $?$ & 0,1258526 & 8,67 & $0,000 * * *$ \\
\hline Setor alimentos e bebidas & $?$ & 0,027134 & 0,82 & 0,412 \\
\hline Setor comércio & $?$ & 0,0388719 & 1,67 & $0,096^{*}$ \\
\hline Setor construção & $?$ & 0,116927 & 3,96 & $0,000 * * *$ \\
\hline Setor eletroeletrônico & $?$ & 0,0315312 & 0,77 & 0,440 \\
\hline Setor energia elétrica & $?$ & $-0,0073594$ & $-0,38$ & 0,702 \\
\hline Setor máquinas industriais & $?$ & $-0,0291167$ & $-0,51$ & 0,608 \\
\hline Setor mineração & $?$ & 0,0103764 & 0,26 & 0,797 \\
\hline Setor minerais não metálicos & $?$ & 0,0025545 & 0,12 & 0,901 \\
\hline Setor outros & $?$ & $-0,0658189$ & $-3,29$ & $0,001 * * *$ \\
\hline Setor papel e celulose & $?$ & $-0,0537169$ & $-2,81$ & $0,005 * * *$ \\
\hline Setor petróleo e gás & $?$ & 0,0050336 & 0,16 & 0,873 \\
\hline Setor química & $?$ & 0,0112639 & 0,45 & 0,655 \\
\hline Setor siderurgia e metalurgia & $?$ & $-0,0028227$ & $-0,05$ & 0,963 \\
\hline Setor software e dados & $?$ & 0,0511689 & 2,00 & $0,047 * *$ \\
\hline Setor telecomunicações & $?$ & 0,0441924 & 1,84 & $0,067^{*}$ \\
\hline Setor têxtil & $?$ & 0,024768 & 0,94 & 0,350 \\
\hline Setor transporte e serviço & $?$ & 0,0061039 & 0,18 & 0,860 \\
\hline $\mathrm{R}^{2} \mathrm{a}=26,61 \%$ & \multicolumn{2}{|c|}{$\mathrm{F}=0,00 * * *$} & \multicolumn{2}{|c|}{$\mathrm{N}=309$} \\
\hline
\end{tabular}

Significância estatística ao nível de $1 \%, 5 \%$ e $10 \%$ é indicada por $* * *, * *$ e $*$, respectivamente.

De acordo com a Tabela 7, o modelo é significante, considerando-se um nível de significância de $1 \%$, conforme teste $\mathrm{F}$ e tem poder explicativo de $26,6 \%$, nos termos do $\mathrm{R}^{2}$ ajustado, e "n" igual a 309, pois, apesar de a amostra contar com 315 empresas, houve a exclusão de seis empresas que apresentaram valores extremos (outliers).

Constata-se que as variáveis Tamanho, Endividamento, Setor Agro e Pesca e Setor Construção são significantes ao nível de $1 \%$ e apresentam coeficiente positivo. As variáveis
Setor Papel e Celulose e Setor Petróleo e Gás, também significantes ao nível de $1 \%$, apresentam coeficiente negativo.

Foram ainda significantes as variáveis Governança Corporativa e Setor Telecomunicações, ao nível de 5\%, apresentando coeficiente positivo, bem como as variáveis Setor Comércio e Setor Têxtil, significantes ao nível de $10 \%$, ambas com coeficiente positivo.

Desta feita, no presente modelo, as variáveis Tamanho, 
Endividamento, Governança Corporativa, Setor Agro e Pesca, Setor Comércio, Setor Construção, Setor Telecomunicações e Setor Têxtil impactam positivamente o nível de disclosure, enquanto as variáveis Setor Papel e Celulose e Setor Petróleo e Gás o impactam negativamente.

Assim, empresas maiores, mais endividadas, e que aderem aos níveis diferenciados da BM\&FBovespa, apresentam maiores níveis de disclosure acerca do AVP, o mesmo ocorrendo com os setores Agro e Pesca, Comércio, Construção, Telecomunicações e Têxtil. Ao contrário, nos setores Papel e Celulose e Petróleo e Gás verificou-se influência negativa.

\section{CONCLUSÕES}

A pesquisa teve por objetivo levantar os graus de cumprimento às orientações de divulgação definidas no CPC 12 pelas companhias listadas na BM\&FBovespa e investigar características capazes de explicar a aderência das firmas ao disclosure, além daquela exigida em norma.

Os graus de cumprimento às orientações de divulgação definidas no CPC 12 foram verificados por meio de métrica de pesquisa desenvolvida a partir dos requisitos de divulgação contidos no $\mathrm{CPC} 12$, a qual reuniu 17 itens. Após aplicação dessa métrica, obteve-se o Índice de Disclosure de AVP apresentado pelas firmas brasileiras.

A amostra da pesquisa reuniu as empresas listadas na BM\&FBovespa no exercício de 2010, excluindo-se aquelas classificadas no setor de finanças e seguros, por apresentarem certas particularidades que as diferenciam das demais; aquelas cujas DFPs do exercício de 2010 não foram disponibilizadas no portal eletrônico da BM\&FBovespa; e aquelas que divulgaram expressamente que não realizaram AVP no período, totalizando 315 empresas.

De maneira geral, verificou-se um baixo cumprimento das orientações de divulgação do normativo, reforçando as descobertas de Ponte, Oliveira e Cavalcante (2010), que também mostraram ter havido um baixo grau de cumprimento das práticas de divulgação quando do início de vigência das leis $\mathrm{n}^{\circ} 11.638 / 2007$ e $\mathrm{n}^{\circ} 11.941 / 2009$.

Corroborando essa afirmação, verificou-se que, das 315 empresas da amostra final, apenas 138 comentaram acerca do AVP, enquanto 177 não divulgaram nenhuma informação sobre o assunto. Verificou-se, ainda, que dos 17 itens de evidenciação incluídos na métrica, 14 foram divulgados por menos de $50 \%$ dessas 138 companhias, bem como que nenhuma delas apresentou todos os itens de evidenciação requeridos pelo $\mathrm{CPC} 12$, sendo de aproximadamente $47 \%$ o maior Índice de Disclosure do AVP alcançado.

Apesar de tal realidade, destaca-se que as companhias já relacionam frequentemente itens de evidenciação importantes, como a descrição pormenorizada dos itens objeto das mensurações a valor presente, as premissas utilizadas pela administração e as taxas de juros aplicadas.

Por meio de testes de diferenças de médias, constatouse que as variáveis Setor Construção, Internacionalização, Firma de Auditoria e Governança Corporativa estão associadas às empresas de maiores níveis de disclosure.

$\mathrm{Na}$ Análise de Regressão, verificou-se que as variáveis Tamanho, Endividamento, Governança Corporativa, Setor Agro e Pesca, Setor Comércio, Setor Construção, Setor Telecomunicações e Setor Têxtil impactam positivamente o nível de disclosure, enquanto as variáveis Setor Papel e Celulose e Setor Petróleo e Gás o impactam negativamente.

Desse modo, não se pode rejeitar a hipótese de que o disclosure relativo ao AVP pode ser explicado por fatores econômicos, patrimoniais e institucionais.

Ressalta-se que a presente pesquisa apresenta limitações, já que o estudo foi realizado tomando-se por base apenas o exercício de 2010. Sugere-se a realização de novas pesquisas sobre disclosure do AVP, envolvendo outros exercícios, ou, ainda, sobre disclosure pela ótica de outros $\mathrm{CPCs}$, devido à importância do assunto para $\mathrm{o}$ mercado de capitais e a economia brasileira, bem como a inclusão de outros fatores econômicos, patrimoniais e institucionais não considerados na presente pesquisa.

\section{REFERÊNCIAS}

ALENCAR, R. C. Nível de disclosure e custo de capital próprio no mercado brasileiro. 2007. 104 p. Tese (Doutorado em Ciências Contábeis) - Programa de Pós-Graduação em Ciências Contábeis, Departamento de Contabilidade e Atuária, Faculdade de Economia, Administração e Contabilidade, Universidade de São Paulo, São Paulo, 2007. Disponível em: <http://www.teses. usp.br/teses/disponiveis/12/12136/tde-14032008120509/pt-br.php>. Acesso em: 24 out. 2011.

AQUINO, D. R. B.; FERREIRA, V. F. Análise do nível de evidenciação dos itens compulsórios e não compulsórios: um estudo nos relatórios contábeis da Petrobras. Revista Universo Contábil, Blumenau, v. 3, n. 1, p. 7-26, 2007. Disponível em: <http:// proxy.furb.br/ojs/index.php/universocontabil/ article/view/139/98>. Acesso em: 23 out. 2011.

BACKES, R. G. Evidenciação do capital intelectual: análise de conteúdo dos relatórios de administração de companhias abertas brasileiras. 2005. 172 p. Dissertação (Mestrado em Ciências Contábeis) - Universidade do Vale do Rio dos Sinos, São Leopoldo, Rio Grande do Sul, 2005.

BALL, R.; KOTHARI, S. P.; ROBIN, A.. The effect of international institutional factors on properties of accounting earnings. Journal of Accounting and Economics, v. 29, p. 1-51, 2000.

BARDIN, Laurence. Análise de conteúdo. São Paulo: Edições 70, 2011.

BM\&FBOVESPA. Empresas listadas. Disponível em: $\quad<$ http://www.bmfbovespa.com.br/ciaslistadas/empresas-listadas/BuscaEmpresaListada. aspx?idioma=pt-br $>$. Acesso em: 9 out. 2011.

BOVA, F.; PEREIRA, R.. The determinants and consequences of heterogeneous IFRS compliance levels following mandatory IFRS adoption: evidence from a developing country. Social Science Research Network, 2010. Disponível em: $<$ http://papers.ssrn.com/sol3/papers.cfm?abstract id=1542240> . Acesso em: 21 jan. 2012. 
BRASIL. Lei $n^{\circ}$. 6.404, de 15 de dezembro de 1976. Dispõe sobre as Sociedades por Ações. Diário Oficial [da] República Federativa do Brasil, Brasília, DF, 17 dez. 1976.

Lei $\mathrm{n}^{\circ}$ 11.638, de 28 dezembro de 2007. Altera e revoga dispositivos da Lei $\mathrm{n}^{\circ}$ 6.404, de 15 de dezembro de 1976, e da Lei $\mathrm{n}^{\circ} 6.385$, de 7 de dezembro de 1976, e estende às sociedades de grande porte disposições relativas à elaboração e divulgação de demonstrações financeiras. Diário Oficial [da] República Federativa do Brasil, Poder Executivo, Brasília, DF, 28 dez. 2007.

Lei $n^{\circ} 11.941$, de 27 de maio de 2009. Altera a legislação tributária federal relativa ao parcelamento ordinário de débitos tributários; concede remissão nos casos em que especifica; institui regime tributário de transição e dá outras providências. Diário Oficial [da] República Federativa do Brasil, Poder Executivo, Brasília, DF, 28 mai. 2009.

CARNEIRO, R. B. A. Divulgação de informações sobre instrumentos financeiros e riscos bancários: uma análise comparativa. 2008. 82 p. Dissertação (Mestrado em Controladoria e Contabilidade) - Programa de Pós-Graduação em Ciências Contábeis, Departamento de Contabilidade e Atuária, Faculdade de Economia, Administração e Contabilidade, Universidade de São Paulo, São Paulo, 2008. Disponível em: <http://www.teses. usp.br/teses/disponiveis/12/12136/tde-27032009124526/en.php> . Acesso em: 23 out. 2011.

CPC. Comitê de Pronunciamentos Contábeis. CPC 12: Ajuste a Valor Presente. 2008. Disponível em: $<$ http://www.cpc.org.br/pdf/CPC_12.pdf $>$. Acesso em: 2 nov. 2011

CPC 26 (R1): Apresentação das demonstrações contábeis. 2011. Disponível em: <http://www.cpc. org.br/mostraAudiencia.php?id_audiencia $=85>$. Acesso em: 24 out. 2011.

COSTA, F. M.; GOLDNER, F.; GALDI, F. C. Análise dos fatores que influenciam no disclosure dos maiores bancos brasileiros. In: CONGRESSO USP DE CONTROLADORIA E CONTABILIDADE, 7., 2007, São Paulo. Anais... São Paulo: USP, 2007. Disponível em: <http://www.congressousp.fipecafi. org/artigos72007/687.pdf $>$. Acesso em: 3 mar. 2012 .

CRUZ, C. V. O. A.; LIMA, G. A. S. F. Reputação corporativa e nível de disclosure das empresas de capital. Revista Universo Contábil, Blumenau, v. 6, n. 1, p. 85-101, 2 fev. 2010. Disponível em: <http:// proxy.furb.br/ojs/index.php/universocontabil/ article/view/838/1151>. Acesso em: 23 out. 2011.

CUNHA, J. V. A.; COELHO, A. C. D.. Regressão linear múltipla. In: CORRAR, L. J.; PAULO, E.; DIAS FILHO, J. M.. Análise multivariada para os cursos de administração, ciências contábeis e economia. 1. ed.. São Paulo: Atlas, 2011.

CUNHA, J. V. A.; RIBEIRO, M. S. Divulgação voluntária de informações de natureza social: um estudo nas empresas brasileiras. Revista de Administração eletrônica, Universidade de São Paulo, São Paulo, v. 1, n. 1, art. 6, 2008. Disponível em: <http:// www.rausp.usp.br/Revista_eletronica/v1n1/artigos/ v1n1a6.pdf $>$. Acesso em: $\overline{2} 3$ out. 2011.
CVM. Comissão de Valores Mobiliários. Deliberação $\mathrm{n}^{\mathrm{o}}$ 539, de 14 de março de 2008. Aprova o Pronunciamento Conceitual Básico do CPC que dispõe sobre a estrutura conceitual para a elaboração e apresentação das demonstrações contábeis. Diário Oficial [da] República Federativa do Brasil, Poder Executivo, Brasília, DF, 17 mar. 2008.

DANTAS, J. A. et al. A dualidade entre os benefícios do disclosure e a relutância das organizações em aumentar o grau de evidenciação. Revista Economia \& Gestão, PUC Minas, Belo Horizonte, v. 5, n. 11, p. 56-76, 2005. Disponível em: <http://periodicos. pucminas.br/index.php/economiaegestao/article/ view/40/34>. Acesso em: 16 out. 2011.

ERNST \& YOUNG TERCO. IFRS Journal, $\mathrm{n}^{\circ}$ 13, Mar. 2011. Disponível em: <http://www. ey.com/Publication/vwLUAssets/IFRS Journalmarco_2011/\$FILE/IFRS journal mar.2011_final.pdf $>$. Acesso em: 23 out. 2011.

FEKETE, S.; MATIS, D.; LUKÁCS, J.. Factors influencing the extent of corporate compliancewith IFRS - the case of hungarian listed companies. Social Science Research Network, 2008. Disponível em: $<$ http://papers.ssrn.com/sol3/ papers.cfm?abstract $\mathrm{id}=1295722$ > . Acesso em: 23 out. 2011.

FIPECAFI. Manual de contabilidade societária: aplicável a todas as empresas de acordo com as normas internacionais e o CPC. São Paulo: Atlas, 2010 .

GIL, A. C.. Como elaborar projetos de pesquisa. 4. ed. São Paulo: Atlas, 2009.

HEALY, P. M.; PALEPU, K. G. Information asymmetry, corporate disclosure, and the capital markets: a review of the empirical disclosure literature. Journal of Accounting and Economics, v. 31, p. 405-440, 2001.

Teoria da contabilidade. 5. ed. São Paulo: Atlas, 1997.

LIMA, G. A. S. F. Utilização da teoria da divulgação para avaliação da relação do nível de disclosure com o custo da dívida das empresas brasileiras. 2007. 108 p. Tese (Doutorado em Controladoria e Contabilidade) - Faculdade de Economia, Administração e Contabilidade, Universidade de São Paulo, São Paulo, 2007. Disponível em: <http:// www.teses.usp.br/teses/disponiveis/12/12136/tde26112007-165145/pt-br.php>. Acesso em: 3 mar. 2012.

FONSECA, J. A. S.; BRITO, G. A. S. Conservadorismo nos resultados contábeis dos bancos em Portugal. In: CONGRESSO USP DE CONTROLADORIA E CONTABILIDADE, 9., 2009, São Paulo. Anais... USP: São Paulo, 2009. Disponível em: $<$ http://www.congressousp.fipecafi. org/artigos92009/174.pdf>. Acesso em: 20 out. 2011.

LIMA, V. S. et al. Determinantes da convergência aos padrões internacionais de contabilidade no Brasil. In: CONGRESSO ANPCONT, 4., 2010, Natal. Anais... Natal: Anpcont, 2010. CD-ROM.

LOPES, A. B.; MARTINS, E.. Teoria da contabilidade: uma nova abordagem. São Paulo: Atlas, 2005. 
MAPURUNGA, P. V. R. et al. Determinantes do nível de disclosure de instrumentos financeiros derivativos em firmas brasileiras. Revista Contabilidade e Finanças, São Paulo, v. 22, n. 57, 2011. Disponível em $<$ http://www.scielo.br/scielo.php?script=sci arttext\&pid $=$ S1519-70772011000300003\&lng $=\overline{\mathrm{pt}}$ \&nrm=iso>. Acesso em 21 mar. 2012.

MELO, F. M. A.; PONTE, V. M. R.; OLIVEIRA, M. C. Análise das práticas de evidenciação de informações avançadas e não-obrigatórias nas demonstrações contábeis das empresas brasileiras. RCO - Revista de Contabilidade e Organizações, São Paulo, v. 1, n. 1, p. 30-42, 2007. Disponível em: <http:// www.rco.usp.br/index.php/rco/article/view/14/8>. Acesso em: 3 mar. 2012.

MENESES, A. F.; PONTE, V. M. R.; MAPURUNGA, P. V. R. Disclosure de ativos intangíveis em empresas brasileiras. In: CONGRESSO ANPCONT, 5., 2011, Vitória. Anais... Vitória: Anpcont, 2011. Disponível em: <http://www.furb.br/especiais/ download/722739-377079/215-2.pdf>. Acesso em: 25 out. 2011

MORIBE, A. M.; PANOSSO, A.; MARRONI, C. H. Um enfoque sobre correção monetária integral e ajuste a valor presente em conformidade com as normas internacionais de contabilidade. Revista Enfoque: Reflexão Contábil, Maringá, v. 6, n. 1, p. 17-28, 2007. Disponível em: <http://periodicos.uem.br/ ojs/index.php/Enfoque/article/view/3577/4342>. Acesso em: 22 out. 2011

MOURA, G. D. et al.. Boas práticas de governança corporativa e evidenciação obrigatória dos ativos intangíveis. In: CONGRESSO USP DE CONTROLADORIA E CONTABILIDADE, 11., São Paulo. Anais... São Paulo: USP, 2011. Disponível em: $<$ http://www.congressousp.fipecafi. org/artigos112011/507.pdf>. Acesso em: 16 out. 2011.

MURCIA, F. D. Fatores determinantes do nível de disclosure voluntário de companhias abertas no Brasil. 2009. 173 p. Tese (Doutorado em Controladoria e Contabilidade) - Programa de PósGraduação em Ciências Contábeis, Departamento de Contabilidade e Atuária, Faculdade de Economia, Administração e Contabilidade, Universidade de São Paulo, São Paulo, 2009. Disponível em: <http:// www.teses.usp.br/teses/disponiveis/12/12136/tde16122009-121627/pt-br.php>. Acesso em: 4 mar. 2012.

OWUSU-ANSAH, S.. The impact of corporate attributes on the extent of mandatory disclosure and reporting by listed companies in Zimbabwe. The International Journal of Accounting, v. 33, p. 605-631, 1998.

PEREIRA, D. M. V. G. et al. Um estudo sobre a relação entre o lucro contábil e o disclosure das companhias abertas do setor de materiais básicos: evidências empíricas no mercado brasileiro de capitais. In: CONGRESSO ANPCONT, 2., 2008, Salvador. Anais... Salvador: Anpcont, 2008. Disponível em: $\quad<$ http://www.anpcont.com.br/site/docs/ congressoII/02/CUE093.pdf $>$. Acesso em: 4 mar. 2012.

PONTE, V. M. R.; OLIVEIRA, M. C.; CAVALCANTE, D. S. Análise das práticas de divulgação do ajuste a valor presente (AVP) pelas companhias listadas na BM\&FBOVESPA. In: CONGRESSO USP DE CONTROLADORIA E CONTABILIDADE, 10. 2010, São Paulo. Anais... USP: São Paulo, 2010. Disponível em: $<$ http://www.congressousp.fipecafi. org/artigos102010/365.pdf>. Acesso em: 22 out. 2011 .

QUEIROZ, L. M. et al. Ajuste a valor presente solicitado pela lei $\mathrm{n}^{\circ}$ 11.638/07: um estudo com as empresas de aviação civil brasileira em 2008. In: CONGRESSO USP DE INICIAÇÃO CIENTÍFICA EM CONTABILIDADE, 7., 2010, São Paulo. Anais... USP: São Paulo, 2010. Disponível em: <http:// www.congressousp.fipecafi.org/artigos 102010/243. pdf $>$. Acesso em: 22 out. 2011.

SILVA, R. L. M. Divulgação de informações e liquidez de ações: evidências do setor de siderurgia e metalurgia do Brasil. 2009. 152 p. Dissertação (Mestrado em Controladoria e Contabilidade) - Faculdade de Economia, Administração e Contabilidade de Ribeirão Preto, Universidade de São Paulo, Ribeirão Preto, 2009. Disponível em: <http://www.teses. usp.br/teses/disponiveis/96/96133/tde-06052009173652/pt-br.php>. Acesso em: 23 out. 2011.

TEIXEIRA, S. C. A relação entre a adoção de práticas recomendadas de governança corporativa e o nível de evidenciação. 2010. 103 p. Dissertação (Mestrado em Controladoria e Contabilidade) Programa de Pós-Graduação em Controladoria e Contabilidade, Universidade de São Paulo, São Paulo, 2010.

VERRECCHIA, R.. Essays on disclosure. Journal of Accounting and Economics, v. 22, p. 97-180, 2001.

YAMAMOTO, M. M.; SALOTTI, B. M.. Informação contábil: estudos sobre a sua divulgação no mercado de capitais. São Paulo: Atlas, 2006. 